\title{
A HISTÓRIA E SEUS SILÊNCIOS: HONRARÁS A TU PADRE Y A TU MADRE, DE CRISTINA FALLARÁS
}

\author{
Joyce Rodrigues Ferraz-Infante ${ }^{1}$ \\ Honra teu pai e tua mãe, para que te vá bem, e vivas \\ muito tempo sobre a terra. (Efésios 6:2,3)
}

Resumo: O romance Honrarás a tu padre y a tu madre, da escritora espanhola Cristina Fallarás, trata das consequências da Guerra Civil e da repressão franquista na sociedade espanhola da atualidade. Por meio da recuperação de memórias e acontecimentos do passado familiar que haviam sido silenciados, a narradora - que não por acaso possui o mesmo nome da autora - questiona sua própria história pessoal e a História de seu país. O propósito deste trabalho é evidenciar o processo de ressignificação identitária levado a cabo pela personagem, a partir das contribuições de Michael Pollak, sobre memória e identidade, e de Clara Valverde Gefaell, sobre transmissão geracional do trauma da violência política do século XX na Espanha.

Palavras-chave: Literatura Espanhola Contemporânea; Guerra Civil Espanhola; Memória.

Substract: The novel Honrarás a tu padre y a tu madre, by the Spanish writer Cristina Fallarás, deals with the consequences of the Civil War and Franco's repression in Spanish society today. Through the recovery of memories and events from the family past that had been silenced, the narrator - who not by chance has the same name of the author - questions her own personal history and the History of her country. The purpose of this work is to highlight the process of identity resignification carried out by the character, based on the contributions of Michael Pollak, on memory and identity, and Clara Valverde Gefaell, on the generational transmission of the trauma of political violence in the 20th century in Spain. Keywords: Contemporary Spanish Literature; Spanish Civil War; Memory.

1 Professora Doutora de Literaturas de Língua Espanhola no Departamento de Letras/DL e no Programa de Pós-Graduação em Literatura/PPGLit da Universidade Federal de São Carlos. E-mail: ferrazrj@ufscar.br 
Em 2018, a jornalista e escritora espanhola Cristina Fallarás publica Honrarás a tu padre y a tu madre. A obra trata da recuperação de memórias e histórias de uma família da classe alta espanhola, que, a fim de representar uma vida conjugal aparentemente estável e feliz, optou por calar traumas e feridas de um passado marcado pela Guerra Civil e pela ditadura de Francisco Franco. A protagonista - que, não por acaso, possui o mesmo nome da autora -, Cristina Fallarás se propõe a desvelar e revelar os silêncios que a privaram de um avô paterno e a questionar os valores que lhe transmitiram os avós maternos. Interroga-se sobre a própria vida de privilégios e se esforça para se compreender e se ressignificar como parte de um contexto familiar, social e histórico bastante mais amplo e complexo do que a fartura de que desfrutava fazia supor, já que o bem-estar ocultava a repressão da ditadura franquista. Nesse sentido, as palavras iniciais do romance expressam, de forma contundente, a determinação que orientará a protagonista: "Me llamo Cristina y he salido a buscar a mis muertos. Caminando. Buscar a mis muertos para no matarme yo. ¿Para vivir? No estoy segura. Convocarlos, dialogar con mis muertos." (FALLARÁS, 2018, p.11) ${ }^{2}$. Ao buscar os seus mortos - entre eles, o avô paterno, fuzilado por "vermelho" em 1936, e o avô materno, militar franquista, que comandava pelotões de fuzilamento na mesma época -, Cristina busca a si mesma. "Yo soy la historia de ellos" (p.65), afirma a personagem. Com esse intuito, ao resgatar memórias silenciadas pela família - nunca se falava do avô assassinado -, a protagonista procura recuperar uma parte de si que se mantinha enterrada na fossa comum do esquecimento junto com os restos mortais do avô e de milhares de vítimas que como ele simplesmente não existiam para os vencedores da Guerra Civil - "No conocí al Félix Chico. No existe su historia. Hasta eso le negaron." (p.33) -. Como contraponto, Cristina expõe suas recordações do outro avô, o militar franquista, cujas histórias de guerra eram motivo de orgulho familiar, narrativas dignas de serem contadas, repetidas vezes, para que se fixassem na memória de filhos, netos e futuras gerações - "Y entonces yo crucé a nado el Bidasoa para unirme a las tropas del generalísimo Franco', explicaba él una y otra vez. [...] ¿ ¿Y cuando estaba tomando un aperitivo en la terraza de Imperia y llegó un rojo? ¿Os he contado como le abrí la tripa con un tenedor?" (p.195-196) -. Cristina se defronta, portanto, com vertentes opostas de uma mesma história, a silenciada e a aclamada, e se propõe a deslindá-las para tentar repropor a própria construção identitária, sua história, que emerge da história de sua família e de seu país - "La historia soy yo" (p.65), declara -, fundindo narrativas e identidade.

O título, Honrarás a tu padre y a tu madre, que reproduz o quinto mandamento da Lei de Deus na tradição judaico-cristã, alude de forma irônica ao nacional-catolicismo que marcou na Espanha o regime de Francisco Franco e o respeito aos antepassados adeptos (e beneficiários) do regime como algo inquestionável. O romance - que também pode ser lido como autoficção (ALBERCA, 2007) ou metaficção (HUTCHEON, 1984), apresenta fotos de família e de outros arquivos que conferem autenticidade aos fatos narrados -, se estrutura em dois planos temporais e narrativos que se alternam e se complementam: um primeiro plano situado no presente da protagonista, Cristina Fallarás, que, por meio de uma voz em

2 Nas próximas referências ao livro Honrarás a tu padre y a tu madre, de Cristina Fallarás, constará apenas o número da página da citação entre parênteses. 
primeira pessoa, narra em tom intimista e subjetivo o processo de recuperação das memórias familiares e seus silêncios, os quais submete a constantes questionamentos, interpretações e avaliações pessoais; e um segundo plano, mais objetivo, que apresenta, por meio de uma voz narrativa de terceira pessoa, a história ou parte da história dos antepassados da protagonista, os avós maternos - o coronel Pablo Sánchez (Juárez) Larqué e María José Íñigo Blázquez - e os avós paternos - Félix Fallarás e Presentación Pérez. Trata-se, portanto, de uma narrativa dentro da narrativa, uma vez que a personagem Cristina narra o seu processo de recuperação de memórias próprias e alheias e apresenta a história que constrói sobre os antepassados, a partir da reelaboração do pouco ou quase nada que sabe - ou pensa saber - sobre os fatos e as personagens - "Si la construcción de nuestra memoria es una reelaboración que jamás podrá ser probada ni, por lo tanto, refutada, ¿qué vendría a ser la construcción de nuestra desmemoria? ¿Con que piezas de Lego nos manejamos, criaturas, para montar aquellos recuerdos que se nos hurtaron?” (p.79).

O relato que escreve Cristina tem como vértice o dia 5 de dezembro de 1936 - "el punto en el que se cruzan todas y cada una de sus partes, desde donde parten las cosas hacia el futuro y hacia el pasado, y que sin ese punto no serían nada." (p.78) - Nesse dia, afirma a narradora, "se cruzaron todos los personajes que construyen mi propio personaje" (p.78), Félix Fallarás, Presentación Pérez e Pablo Sánchez (Juárez) Larqué. Em dezembro de 1936, a Espanha estava em Guerra Civil. Em Saragoça, os militares sublevados contra a II República haviam triunfado e tomado o governo provincial e, como ocorria em todos os territórios controlados pelas forças do exército franquista, se executava na cidade uma intensa política de terror e repressão contra toda e qualquer pessoa que não apoiasse o golpe de estado, que se autodenominava Movimento Nacional. Conta Cristina que, nesse dia 5 de dezembro, Félix Fallarás, seu avô paterno - carpinteiro de teatro, 35 anos, casado com Presentación Pérez e pai de Luisín e Félix, de seis e dois anos -, foi levado de casa e fuzilado no muro do cemitério de Torrero, em Saragoça, ao lado de outros homens. Presentación, a jovem esposa, apesar das rezas e dos esforços para obter o apoio de quem pudesse intervir pelo marido, não pôde salvá-lo. Dias antes, Pablo Sánchez (Juárez) Larqué, o avô materno de Cristina - um jovem rico, de pele morena, com traços de indígena mexicano, e bisneto de Benito Juárez, presidente do México entre 1858 e 1872 -, depois de unir-se às tropas do general Francisco Franco, fora nomeado alferes e enviado a Saragoça. Segundo a narradora, no dia 5 de dezembro de 1936, o alferes Pablo acompanhava a seu capitão, o qual comandou o fuzilamento que ocorreu no cemitério de Torrero, onde Félix Chico, como era conhecido, foi assassinado, apesar de não ser militante político ou sindicalista, como o pai, também Félix Fallarás - o Félix Viejo -, membro da UGT (Unión General de Trabajadores) - a quem os golpistas queriam efetivamente executar. Em outras palavras: o homem que viria a ser o avô materno de Cristina participou do fuzilamento do homem que viria a ser seu avô paterno.

La historia de esos tres personajes - porque son tres los que me interesan - pudo ser muy parecida a esto que acabo de contar. Las vidas de Pablo Sánchez (Juárez) Larqué, Presentación Pérez y Félix Fallarás, el Félix Chico, se cruzan por primera vez en España en 1936, poco tiempo después de que se declare la Guerra Civil, el 
mismo año que Félix Fallarás muere fusilado en unas circunstancias muy similares a las narradas. (p.78)

No pós-guerra e na ditadura, Pablo Sánchez (Juárez) Larqué, militar católico e franquista convicto, prosperou. Terminada a guerra, em 1939, da qual saiu coberto de medalhas, se casou com a aristocrata María Josefa Íñigo Blázquez, a Jefa - filha do coronel Julio Íñigo Bravo, Barão de Apizarrena -, com quem teve três filhos. Tornou-se advogado e ascendeu a coronel do exército. Segundo a narradora, o coronel e a esposa não se lembravam dos tempos de fome do pós-guerra, os quais, dependendo da posição de quem os vive, "puede ser una idea lucrativa, y a ellos la miseria les pasó de largo.” (p.148) -:

En Zaragoza, como en el resto de España, los muertos, los exiliados, los escondidos, los presos, los mudos habían dejado huecos en la realidad que la ciudad no lograba digerir, y las cosas sucedían de forma espesa y dolorosa, ulcerada. Solo los militares y los curas, además de un puñado de familias, parecían conservar el ritmo habitual del vivir. Sobre el resto de los habitantes se había posado una capa marrón de pesadumbre e incluso los trámites más cotidianos parecían penosas tareas. De los agujeros de chaquetones y zapatos brotaba el hálito acuoso de la humillación. (p.134)

Passados vinte anos daquele dia 5 de dezembro - em que o carpinteiro e o alferes se cruzaram no cemitério de Torrero como vítima e verdugo -, se produz um novo encontro das famílias Fallarás e Sánchez (Juárez) numa agência bancária de Saragoça, onde María Jesús, filha do então tenente coronel Pablo Sánchez (Juárez) Larqué, conhece o novo funcionário, Félix Fallarás - o caçula de Presentación e Félix Chico -, que administrará as contas de seu pai. Apesar das diferenças de origem e classe social - "quería casarse con la hija de la Jefa y el coronel, qué osadía, quería casarse él, un hijo del hambre, un hijo de la muerte merecida, un nieto del teatro y el socialismo" (p.169) -, María Jesús e Félix se casam em 1967. Cinquenta anos depois, Cristina examina uma fotografia da cerimônia de casamento de seus país - "La terca, reverente, casi infantil seriedad de ella, que con veintiún años ha decidido dejar de pertenecer. La de él, que consciente de ello, hará lo mismo" (p.216) - e entende que o filho de Presentación e a filha do coronel "se profesan y se han profesado siempre un amor sin fisuras. Nada se sitúa por encima de ese amor, ni sus antepasados, ni sus descendientes, ni siquiera ellos mismos por separado. Así es.” (p.210).

Cristina, portanto, é fruto de duas realidades histórico-sociais opostas e, em princípio, inconciliáveis: o mundo de triunfos e privilégios representado pelos avós maternos, o coronel e a Jefa, que nasceram em berço de ouro, venceram a Guerra Civil, obtiveram vantagens e privilégios com essa vitória e multiplicaram a fortuna herdada como seria de se esperar de pessoas pretensamente honradas e respeitáveis numa Espanha miserável; e o mundo de carências, amargura, fome e humilhação representado pela avó paterna, Presentación - a figura do avô paterno simplesmente não existia -, mulher de origem pobre, trabalhadora, que se acostumou a obedecer, agradecer e aceitar o quinhão mesquinho que lhe era dedicado, com a devida resignação que cabia aos que haviam perdido a guerra e a dignidade. 
No tengo un primer recuerdo de Félix Fallarás hijo, el Félix Chico. Al coronel y Presentación les conocí. Al Félix Chico, evidentemente, no. En algún momento de mi infancia debí de preguntar por él y me debieron de contar que estaba muerto. No conservo memoria de que nadie me dijera nunca que fue fusilado en la Guerra Civil española. No recuerdo en absoluto ninguna referencia a su muerte, y sin embargo alguien debió de contármelo, porque lo sé.

Quién sabe cómo funcionan los mecanismos del silencio, y cómo su contrario. (p.202)

Era como se Félix Chico nunca houvesse existido. Não havia um atestado de óbito, sequer uma lápide em que figurasse seu nome. Como milhares de pessoas assassinadas durante a Guerra Civil e a ditadura de Franco, seus restos mortais, durante décadas, permaneceram ocultos numa fossa comum. Essa estratégia fazia parte de uma política sectária e obsessiva dos vencedores, que tinha como propósito silenciar e desmoralizar os vencidos, por um lado, e recordar e homenagear exclusivamente os próprios mortos, por outro (AGUILAR, 2019, p.230). Além de reconhecimento, as famílias dos que caíram pela autodenominada Nova Espanha receberam pensões e ajuda econômica para exumar, enterrar e prestar tributos aos seus mortos. Os perdedores, salvo contadas exceções, não puderam transladar, identificar ou prestar qualquer homenagem aos seus. Ademais, estava proibido "hablar públicamente de los vencidos, y más aún de aquellos cuyos restos aún yacían en fosas comunes, era un tema absolutamente tabú, y los pocos que se atrevían a mencionarlos solían ser castigados por ello.” (AGUILAR, 2019, p.231-232).

Foi necessário aguardar a morte de Franco e a transição à democracia, a princípio dos anos de 1980, para que se iniciasse por meio de associações - como a Asociación para la Recuperación de la Memoria Histórica, $A R M H$ - um movimento de exumação de fossas comuns e identificação de vítimas em toda a Espanha - que ainda hoje está em andamento -. Em Honrarás a tu padre y a tu madre, Cristina procura nas listas divulgadas na internet por associações como a $A R M H$ o nome de seu avô - "en sus listas iban aparecendo los muertos que quedaron en fosas y caminos, los puertos de tiro y ribazo" (p.82) -, até o dia que o encontra em duas fichas com sumárias informações, as quais haviam sido recolhidas por Julián Casanova no livro intitulado El pasado oculto:

Tras leer las fichas aquellas publicadas en internet, escribí a Julián Casanova, el hombre cuyo libro parecía haber devuelto a Félix Fallarás.

$[\ldots]$

Me respondió al poco rato.

En El pasado oculto, efectivamente, tu abuelo aparece en la vista de víctimas del 5 de diciembre de 1936 y la causa de la muerte, según un registro de defunciones, es "fractura en el cráneo", uno de los diversos eufemismos con que les inscribía el 
encargado de turno.

Por la fecha de la muerte, lo normal es que lo fusilaran en las tapias del cementerio.

Efectivamente, tu abuelo.

EFECTIVAMENTE, TU ABUELO.

De repente, un abuelo. ¡Un abuelo!

Entiéndase que yo no es que tuviera un abuelo asesinado o fusilado en la Guerra Civil española. Ni siquiera un abuelo asesinado a secas o un abuelo que desapareció. No tenía un abuelo en absoluto. No tenía un abuelo por la simple razón de que mi padre no tenía un padre. Punto. Nada. Se llama Elimina el Rencor y Olvida lo Que Pasó. Se llama Rencoroso el Que se Acuerde. Se llama Tú te Callas porque Perdiste la Guerra. Se llama Olvida que Existió. (p.87-88)

Os fuzilamentos faziam parte das ações repressivas - que incluíam torturas, encarceramentos, expropriação de bens, humilhações públicas, cassação de direitos - que utilizaram os golpistas - e depois a ditadura franquista - para reduzir à submissão absoluta toda e qualquer pessoa que resistisse a aceitá-los no poder, que se mantivesse fiel ao regime político destruído - a II República - ou que desejasse permanecer à margem. A repressão era extensiva às famílias dos condenados, uma vez que - além de não poderem realizar o luto ou clamar por justiça - ficavam no mais absoluto desamparo econômico e social (ESPINOSA, 2012). Especialmente dura foi a repressão contra as mulheres. Além do terror, das mortes, da fome, a mulher republicana era vista como imoral porque pleiteava os mesmos direitos e liberdades dos homens. Para ser condenada à prisão, no entanto, não era necessário haver sido militante ou afiliada política durante a República, bastava ser esposa ou mãe de preso, fuzilado ou exilado. Fora da prisão, padeciam humilhações e degradações públicas por parte dos vitoriosos, com o objetivo de fazer com que se sentissem culpadas, arrependidas ou envergonhadas de seu posicionamento político ou social. (ARBANAT, 2013, p.57).

Durante décadas, essa política de violência e terror marcou a vida de milhões de cidadãos espanhóis, a quem não se oferecia mais opção do que apoiar o regime ou calar-se. Daí, o medo a expressar abertamente qualquer emoção ou sentimento de contrariedade e o silêncio como forma de evitar represálias. Devido a esse contexto, segundo Clara Valverde Gafaell (2016, p.72), pessoas que padeceram a violência da guerra e do pós-guerra se abstiveram de expressar por palavras e narrativas seus traumas e sofrimentos para proteger-se, proteger os filhos e poupá-los de sentimentos de raiva, vulnerabilidade, impotência. Como consequência, de acordo com a autora, os filhos dos sobreviventes, ao perceberem que os pais sofriam calados e escondiam sentimentos e informações, padeciam medos e ansiedades de forma inconsciente e incompreensível para eles mesmos. A autora acredita que mais complicada ainda é a situação dos netos dos sobreviventes de uma violência coletiva, uma 
vez que "herdam", “absorvem”, os traumas de seus pais e avós, com o agravante da perda de conexão com o contexto traumático original. "Esto hace que la generación de los nietos lleve una gran carga en el inconsciente a la que es más difícil acceder, porque los años de silencio y de comportamientos que han servido para esconder las emociones dificultan la comprensión del trauma." (VALVERDE, 2016, p.75). Trata-se do que Clara Valverde chama de "Transmissão geracional do trauma da violência política", ou seja, aquilo que não pôde ser dito por medo ou contenção num contexto de guerra ou repressão política foi transmitido dos avós aos pais e dos pais aos netos de forma não verbal e, geralmente, inconsciente. Dessa forma, os netos adquirem, sem dar-se conta e sem desejar, aspectos nocivos do impacto emocional que afetou os avós e os pais décadas antes de seu nascimento, no caso de Cristina, a repressão franquista durante a Guerra Civil Espanhola e a ditadura. Em Honrarás a tu padre y a tu madre, a protagonista comenta uma entrevista de Clara Valverde (2014) sobre a transmissão geracional do trauma:

Parece que a quienes afecta con más saña la TGTVP [transmisión generacional del trauma de la violencia política] es a los nietos. Yo soy nieta. La psicóloga llamada Clara Valverde deja caer en la entrevista las palabras miedo, rabia, bloqueo emocional, anorexia, toxicomanía, enfermedad, muerte.

[...] Me pregunto si tiene que ver con este empeño mío en ir matándome, haber vivido instalada en un estado químico de inconciencia desde que recuerdo. Me pregunto también por qué mi primera reacción ante la TGTVP consiste en burlarme de la tal Valverde y pensar en nuestras excusas. Todos necesitamos alguna excusa para nuestras faltas, nuestra basura. Si has pasado treinta años ciega, más vale que la excusa sea del tamaño de una guerra civil, la peor de todas. (p.81)

Apesar de se reconhecer como neta da violência política de que fala Valverde, Cristina prefere não se ver como vítima e se recusa a utilizar o que chama de TGTVP para justificar seu comportamento autodestrutivo. No entanto, sem dar-se conta, a personagem - ao escrever memórias e histórias pessoais e familiares - realiza um profundo processo de elaboração do passado traumático em sua relação com o presente, o que lhe permite compreender aspectos, até então, adormecidos de seu mundo interior. Segundo Clara Valverde, só é possível curar as feridas transmitidas de uma a outra geração quando se traz para a consciência aquilo que estava no inconsciente, posto que, provavelmente, “el cambio que se necesita esté ligado a una herida relacionada con la identidad personal, familiar o social, o con creencias arraigadas en el bagaje heredado." (VALVERDE, 2016, p.129).

A descoberta da existência de um avô fuzilado em 1936 - “¿Qué coño un abuelo que, hasta un segundo antes de leer su nombre, no existía?” (p.84) - desperta na protagonista tanto a consciência de que sua história pessoal estava incompleta sem memórias ou recordações da existência de Félix Chico - “¿Acaso queda algo más del resto de los protagonistas de esa história? Mi herida queda.” (p.85) - quanto a necessidade de recuperar e reconstruir pela escrita o passado familiar que havia sido enterrado no silêncio - "Nuestra existencia es memoria. Somos finalmente, la idea que queda, recuerdo. Maldigo, pues, a quienes matan 
la memoria." (p.85) -. Portanto, é com o propósito de encontrar a si mesma que Cristina rememora acontecimentos e impressões que marcaram sua infância e juventude, elabora a história de seus avós em relação à história do país, e questiona, enquanto analisa, o seu lugar no tempo-espaço marcado por acontecimentos passados e presentes, num contexto familiar baseado em silêncios e relações de poder - "Las cosas de la Historia, de la historia con mayúscula, modifican nuestras pequeñas, insignificantes existencias." (p.157) -.

"Me llamo Cristina Fallarás Sánchez (Juárez). Fallarás por parte del Félix Chico. Sánchez (Juárez), por la del coronel. Hace ya días que salí a buscar a mis muertos... (p.155)" - repete a protagonista ao longo do livro. Assim sendo, ao reconstruir a história de vida dos antepassados e de si mesma, Cristina procura redefinir o seu lugar social e suas relações com os outros personagens, em busca do que seria a sua identidade. Pode-se entender identidade como o processo de construção de uma definição ou imagem de si mesma que a pessoa realiza ao longo da vida. Esse processo se relaciona diretamente com a interação com outras pessoas, uma vez que, por meio da habilidade para internalizar as atitudes e expectativas dos outros, o "eu" se converte em objeto de reflexão do próprio sujeito. Nesse sentido, a construção da identidade é um processo material, além de cultural e social, que a partir do presente - o que somos? - se relaciona com o passado, onde estão guardados os principais elementos da identidade, e com o futuro - o que queremos ser? -, entendendo-se essa construção como um projeto (LARRÍN, 2003). Em Honrarás a tu padre e a tu madre, se observa o trabalho consciente de Cristina num projeto de reconstrução de uma identidade do passado para o futuro, juntando seus mortos e suas memórias:

En algún momento de la tarde, tras darme una ducha, me enfrenté en el espejo empañado con una mujer.

- ¿Quién eres?

- Nadie ya.

- ¿Quién coño eres?

- Ya veremos. (p.25)

De acordo com Michael Pollak, a identidade, entre outros elementos, se compõe de memórias - pessoais, familiares, da coletividade -, que reforçam os sentimentos de continuidade e coerência de uma pessoa na construção da imagem de si. A memória, como a identidade, também é um fenômeno construído social e individualmente. O que a memória individual grava, recalca, exclui, relembra é resultado de um verdadeiro trabalho de organização consciente e inconsciente, sujeito a constantes flutuações em função do momento em que a memória está sendo expressa. Recorde-se que a memória individual ou coletiva se compõe de acontecimentos vividos pelo indivíduo e também acontecimentos vividos pela coletividade ou pelo grupo a que a se sente pertencer, inclusive aqueles que não se situam em seu espaço-tempo ou no espaço-tempo de seu grupo. (POLLAK, 1992, p.204). 
Para reconstruir a si mesma e redefinir o seu lugar social e suas relações consigo e com os outros - "Toda historia se narra para pertenecer." (p.159) -, a protagonista se despoja de tudo e de todos - "No necesito nada ni a nadie [...].Y por lo tanto puedo escribirme, o sea, elegir el desnudo de mi no pertenencia o de lo contrario." (p.167) - e se dirige ao lugar em que passou parte da infância e adolescência, o Grand Oasis Park, em Tarragona, Barcelona - "Aquí adonde me han traído mis muertos." (p.34) -. Cristina se instala entre os escombros da que havia sido a casa de verão da família no condomínio construído no ocaso da ditadura de Franco, nos anos de 1970, devidamente cercado e vigiado por câmaras de segurança para isolar e resguardar a elite espanhola e seus filhos das influências do exterior. Do pomposo condomínio de exuberantes jardins e paredes imaculadas, apenas restos e sombras deixavam constância do que ali havia existido, o que faz com que a personagem entenda algo que a incomodava na infância: "la sensación de impostura, la impresión de no haber pertenecido a aquello nunca del todo. Como cuando te invitan a una fiesta de gente estupenda, gente rica y limpia, y no puedes dejar de saber lo de tu ropa interior.” (p.54) Nesse sentido, o Grand Oasis pode ser visto como uma alegoria dos mecanismos do governo franquista para salvaguardar seus apaniguados do contato direto com a realidade crua do subdesenvolvimento em que vivia a Espanha ditatorial, isolada por muito tempo do resto da Europa e do mundo e submersa numa economia de base agrícola que só a partir de década de 1950 começa a se transformar lentamente graças à aproximação com os Estados Unidos. Nesse espaço artificialmente concebido para o isolamento dos bem-aventurados, a narradora cresceu e concebeu-se como integrada a esse grupo social a que pertencia o tronco familiar ligado aos seus avós maternos, vencedores da Guerra Civil e usufrutuários das benesses do regime ditatorial. E é como parte desse grupo que Cristina se percebe desorientada, adepta de uma letargia química - "mucho alcohol o algún veneno propicio" (p.80) - que, à semelhança do que ocorre com o condomínio de luxo que se converte em ruína, conduz o indíviduo à inação e a uma espécie de inapetência existencial. É nesse ponto de sua vida que a narradora decide buscar seus mortos, redescobre o avô paterno apagado da história e da História, relê a importância da avó materna e passa a redimensionar-se por meio da narrativa que elabora, amalgamando ficção e memória e cortando fundo na carne daquilo que até então considerava sua identidade.

É na leitura atenta do texto literário que se pode perceber a profundidade que alcança esse processo de reconstrução identitária. Nos trechos do livro dedicados a narrar os acontecimentos que conduziram ao fuzilamento do avó Félix Chico, Cristina modula uma linguagem que combina lirismo e empatia e oferece ao leitor uma imagem marcada por uma delicada sensibilidade da vida da avó Presentación e seu marido - apesar da pobreza com que lidavam diariamente, dividiam uma vida conjugal ancorada no afeto recíproco:

Presentación ordena las piedras sobre el fogón. Encima de la cocina económica de hierro forjado, los cantos robados a la orilla del Ebro parecen animalillos acurrucados para la siesta. Luego los meterá calientes en los bolsillos de los chicos antes de que salgan hacia la escuela. Es su cocina, en su casa, son sus hijos, acaba de llegar su marido. Enumera sus cosas, como cada día a esa misma hora, después de oír la puerta cerrarse. 
Retira el cacillo donde hierve un café insuficiente y acerca la nariz para aspirar lo que será su ración para toda la jornada, vapor de cafeína falsa.

Presentación y Félix Chico conservan pese a los aprietos la alegría de cada momento. Antes del amanecer, ella casi intacta de carne recién despierta y él todavía con el humo del último pitillo flotándole en el pelo. No han tenido nada más, no desean otra cosa, y el tiempo es un fugaz parpadeo que se abre a la oscuridad. Habitualmente, basta un tímido buenos días y un trago de café del hombre sin dormir para que la agarre de la cadera y la conduzca al dormitorio. Su dormitorio. Hasta que amanezca.

Pero este sábado 5 de diciembre no amanecerá. (p.41)

Observe-se a carga de afetividade contida nos pronomes possessivos em "su cocina", "su casa", "sus hijos", "su marido", "sus cosas" - intencionalmente destacados em itálico pela narradora -, os quais intensificam a felicidade de Presentación ao sentir que possui - e que pertence a - uma casa, um lar e uma família. Os pronomes criam uma vinculação afetiva intensa e enfatizam o pertencimento aos dados da realidade a que se referem.

Já na representação das figuras pertencentes ao tronco familiar do lado dos avós maternos, a linguagem é outra e estabelece um fundo contraste com a empregada para configurar literariamente o mundo de Presentación e Félix: o aspecto, as ações e as palavras relacionadas à Jefa e ao coronel Pablo são oferecidas ao leitor num tom que toca algumas vezes o irônico e com muita frequência o brutal:

- Hala, Pablo, vamos.

- El coche está abajo.

Se agarra del brazo de su marido y el principio de odio con que acostumbra a jugar desde el mismo día en que se casaron vuelve a ser orgullo. El varón mide un metro noventa y tres centímetros, viste uno de los uniformes más condecorados, despierta la admiración de hombres y de mujeres por igual, ha ganado la guerra.

Y es el suyo. No hay otro igual en toda la ciudad, y el que hay es suyo. Eso basta para borrar la punta de odio sobre la que ha estado bailando hasta pocos minutos antes.

Aprieta el brazo del militar con su guante crudo de cabritilla y salen al frío de Zaragoza. Un cierzo que corta la respiración arrasa el mediodía y la obliga a estrujarse contra él. Se miran un instante ante el asistente del militar que mantiene la puerta del coche abierta. María Josefa deseó a aquel animal desde el primer momento en que lo tuvo delante, años atrás, recién empezada la guerra, junto a su padre. No lo deseó como se desea a un macho. Deseó el objeto. Jamás había 
visto un ejemplar semejante e inmediatamente supo que sería suyo. Ni entonces ni ahora, nueve años después, frente al asistente, se le ha ocurrido pensar que esa bestia necesitaba atenciones, al menos más allá de las que él solo pueda procurarse. (p.129)

Nesse trecho, à diferença do anterior, os pronomes possessivos utilizados em "su marido", "el suyo", "su guante crudo de cabritilla", "supo que sería suyo" se utilizam para indicar a personalidade da avó María Josefa, a Jefa, mulher possessiva, arrogante e fútil para quem o marido - como as luvas de pelica -, não passa de um objeto notável e digno de ser exibido.

O contraste entre os trechos citados mostra a exploração de um mesmo recurso linguístico, os pronomes possessivos, despertando matizes de significado bastante diversos nos contextos em que surgem. A matéria literária fundamental é, obviamente, a materialidade do texto e é nessa materialidade que se encontram conformados os elementos expressivos que Cristina organiza em seu processo de indagação do próprio passado e do passado espanhol. Ao construir o seu relato, a protagonista, finalmente, se reconhece como neta de duas realidades sociais e políticas espanholas opostas: a de Presentación e Félix Chico, trabalhadores pobres subjugados e silenciados; e a da Jefa e do coronel, aristocratas e militares que os subjugaram e calaram. Do seu texto emerge a diferença fundamental entre o possuir de Presentación, que é essencialmente impregnação afetiva do espaço e dos relacionamentos familiares, e o possuir de María Josefa que é controle, exercício de poder - afinal, ela é "jefa”, a chefa -. Reconhece também como foi conveniente silenciar o passado traumático como forma de manter intactos privilégios de uma classe social que prosperou em cumplicidade com a ditadura - "Quizá todo silencio, todo miedo, toda cobardía estén construidos para poseer, para acumular, para no perder aquello que creemos poseer.” (p.167) -. Num processo profundo de reelaboração da própria narrativa individual, Cristina toma consciência de que é imprescindível conhecer o que ocorreu no passado para se evitar manipulações familiares, políticas e midiáticas sobre o indivíduo e a sociedade - "El silencio se combate, antes, en la família. El primer silencio que se combate es el íntimo, el familiar. Si ese permanece, y con él su cobardía, nada se puede hacer entre los hombres, nada de valor." (218) - . Combatendo o apagamento da figura do avô paterno e elaborando a história desse ramo familiar que o golpe de estado e a Guerra Civil haviam obliterado, Cristina reconstrói-se e reconfigura o sistema de valores que lhe havia sido imposto pelos vencedores. $\mathrm{Na}$ intimidade de seu texto, a voz dos derrotados ganha dimensão capaz de aportar à identidade da personagem-autora uma densa contribuição afetiva e histórica. 


\section{REFERÊNCIAS}

AGUILAR Fernández, Paloma. El primer ciclo de exhumaciones y homenajes a fusilados republicanos en Navarra. Kanchatka. Revista de Análisis Cultural, Universitat de València, nº13, p.227-269, junho/1919.

ALBERCA, Manuel. El pacto ambiguo. De la novela autobiográfica a la autoficción. Madrid, Biblioteca Nueva, 2007.

ARNABAT Mata, Ramón. La represión: el ADN del franquismo español. Cuadernos de Historia, Universidad de Chile, n³9, p.33-59, dezembro/2013.

ESPINOSA Maestre, Francisco. La guerra en torno a la historia que ha de quedar. Hispania Nova. Revista de historia contemporânea, Madrid, nº10, 2012. Disponível em: http://hispanianova.rediris. es/10/dossier/10d021.pdf

FALLARÁS, Cristina. Honrarás a tu padre y a tu madre. $2^{\text {a }}$ ed. Barcelona, Anagrama, 2018.

LARRAÍN, Jorge. El concepto de identidade. Revista FAMECOS, Porto Alegre, no 21, p.30-42, agosto/2003.

HUTCHEON, Linda. Narcissistic narrative: the metafictional paradox. 2 ed. New York, Methuen, 1984.

POLLAK, Michael. Memória e identidade social. Estudos Históricos, Rio de Janeiro, vol. 5, n 10, p. 200-212, 1992.

VALVERDE Gafaell, Clara. Desenterrar las palavras. Transmisión generacional del trauma de la violencia política del siglo XX en el Estado Español. 2a ed. Barcelona, Icaria, 2016.

"Los nietos del franquismo 'heredan' inconscientemente el sufrimiento de sus padres y de sus abuelos". [Entrevista concedida a Elena Cabrera]. eldiario.es, 29/06/2014. Disponível em: https://www. eldiario.es/sociedad/transmision-generacional-violencia-politica-Espana_0_274373476.html 